\title{
Gustav Meyrink'in Kardinal Napellus Öyküsünde Hiyerofani ve Erginlenme
}

\author{
Kadir Albayrak (iD, Sivas \\ doi) https://dx.doi.org/10.37583/diyalog. 802183
}

$\ddot{O} z$

Viyana doğumlu yazar Gustav Meyrink, fantastik konuları ele aldığı çok sayıda eser vermiştir. Yazarın Golem ve Batı Penceresinin Meleği adlı romanları Türkçe'ye çevrilmiştir. Bu çalışmada ele aldığımız eseri ise Kardinal Napellus adlı öyküsüdür. Bu öyküde, Radspieller adlı bir keşişin yaşadığı dinsel değişim anlatılır. Yapılan bu çalışmada, olağanüstü olayların ve dinsel konuların iç içe geçtiği öykü, Mircea Eliade'nin çalışmaları bağlamında ele alınmıştır. Çalışmanın ilk bölümünde hiyerofani, kutsal ve kutsal-dışı gibi kavramlar açıklanmaya çalışılmıştır. Eserin incelendiği bölümde ise Radspieller'in kutsal bir yaşamdan kutsal-dışı bir yaşama geçişinde etkili olan mavi kurtboğan bitkisinin bir hiyerofani olarak tanımlanabileceği ve bu bitkinin erginlenme için önemli bir rol oynadığı sonucuna varılmıştır.

Anahtar Sözcükler: Gustav Meyrink, Kardinal Napellus, Hiyerofani, Kutsal, Erginlenme.

\begin{abstract}
Hierophany and Initiation in Gustav Meyrink's Story Der Kardinal Napellus

The Vienna-born writer, Gustav Meyrink, has produced many works on fantastic topics. His novels such as Der Golem and Der Engel vom westlichen Fenster have been translated into Turkish. The name of the work we dealt with in this study is the story called Der Kardinal Napellus. This story tells us about the religious change that a monk named Radspieller experienced. In this study, the story of extraordinary events and religious issues are handled in the context of the works of Mircea Eliade. In the first part of the study, concepts such as hierophany and sacred and profane are tried to be explained. In the section in which the work is analysed, it is concluded that aconitum napellus plant, which is effective in the transition of Radspieller from a sacred life to a profane life, can be defined as a hierophany, and plays an important role for the initiation.
\end{abstract}

Keywords: Gustav Meyrink, Der Kardinal Napellus, Hierophany, Sacred, Initiation. 


\section{EXTENDED ABSTRACT}

Gustav Meyrink's story Der Kardinal Napellus in which a monk named Radspieller experienced extraordinary events will be discussed in this study. The mentioned work will be tried to be evaluated within the context of the concept of Hierophany which Mircea Eliade deals with. This concept is most generally defined as the manifestation of the sacred. The aim of the study is to identify the way in which the hierophany that we think exists in Meyrink's work reveals itself and to reveal how the Radspieller's religious faith created a spatial change in his life. In the first section of the study, the information based on the concept of hierophany and Eliade's sacred and profane study will be explained, and in the next section where the work is examined, initiation will be examined in Der Kardinal Napellus story in accordance with the information provided by Eliade.

It is defined as hierophany by Mircea Eliade, the manifestation of the sacred, making the sacred feels itself in an object and making it visible to people in this world.

Another important issue that Eliade deals with, apart from the concept of hierophany, is the desire of religious people to be close to the sacred. According to him, a religious man tries to stay in a "sacred universe".

In line with this information given by Eliade, hierophany will be discussed in the next section, because we think that this hierophany is effective in transforming the life of the main figure Radspieller from being a religious person to a non-religious or profan one, who can be defined as a religious person, at least in a certain period of his life. At this point, the efforts of Radspieller to establish a new world for himself in a place where the sacred is not manifested will be evaluated spatially.

In this story of Gustav Meyrink, the old Hieronymus Radspieller used to be a monk and the strange events that happened both when he was a monk and away from civilization were told.

The monastery where Radpieller lived as a monk can be defined as a heterotopia in terms of being a sacred or religious place.

The sacred and profan contrast is manifested in the life story of Radspieller in Meyrink's Der Kardinal Napellus. Radspieller, who prefers to lead a profane life while living a sacred or religious life during his youth, removes himself from the sacred but fails in this regard, because the religious life he wants to leave, constantly follows him with different coincidences.

In the work of Cardinal Napellus by Gustav Meyrink, Radspieller's effort to escape from the sacred and leading a life far from this has failed. Although, it seems that he managed to escape from sacred but he can never get rid of what he wanted to get away with the events that seemed like a coincidence. Even the prophecy was realized in the last situation. The concept of hierophany, which Eliade expresses as the manifestation of the sacred, manifests itself here as the plant of Aconitum Napellus. First, it is seen that this plant, which gushes from the grave of the saint, and the sacred are manifested by a plant. Then, even in a place where Radspieller believes that the sacred cannot reach himself with his desire to be a non-religious person, he confronts this plant and the saint's sacred objects and chases himself. In other words, the search 
for a place where the sacred is not manifested ends with failure and Radspieller has to confront the sacred, even in a place where he believes that the sacred does not touch.

As opposed to the desire of the religious person to be close to the holy one, which he attempted to establish his own universe, Radspieller tried to move away from sacred and wanted to establish a profan universe for himself, in a place where the aconitum napellus plant did not grow. 


\section{Giriş}

1868 yılında Viyana'da doğan yazar Gutsav Meyrink, okültizm taraftarı ve burjuva karşıtıdır. 1903 yılından itibaren Liebe Augustin'de redaktör olarak çalışmış ve Simplizissimus dergisi için yazılar yazmıştır. Yazar olarak büyük başarısını fantastik romanları, Golem (1915), Das grüne Gesicht (1917), Walpurgisnacht (1917) ve Der weiße Dominikaner (1921) ile elde etmiştir. Bu eserler bugün fantastik edebiyatın klasikleri olarak kabul edilir. Meyrink bu romanlarında ve diğer eserlerinde gizli ve Budist etkilerin görüldüğü gizemli dünyaların ve mistik öğretilerin kapılarını aralar (Lutz 1986: 455). Örneğin Golem romanında gerçekliği fantastik olanla harmanlar ve bunu da gizemli toplulukların ve şeytani olanın tekinsizliği ile başarır. Eserde olayların geçtiği Eski Prag, mistisizmin ve esrarlı rüyaların şehri olarak karşımıza çıkar (Martini 1991: 532). Ayrıca Golem romanının yayınlandığı yıl filmi de çekilir (Bark 1997: 136).

Yapılan bu çalışmada Gustav Meyrink'in, Radspieller adında bir keşişin yaşadığ1 sıra dışı olayları anlattığ Kardinal Napellus adlı öyküsü ele alınacaktır. Anılan eser, Mircea Eliade'nin çalışmalarında ele aldığı Hiyerofani kavramı bağlamında değerlendirilmeye çalışlacaktır. Bu kavram, en genel itibariyle kutsalın tezahürü (Eliade 2017c: 139) olarak tanımlanır. Eliade, hiyerofaninin kendini gösterdiği bir mekânın, hangi açıdan önemli olduğunu şöyle açıklar:

\section{Kutsal kendini herhangi bir hiyerofaniyle dişa vurduğunda sadece uzamın türdeşliğinde bir kopuşma yaşanmaz, aynı zamanda çevredeki uçsuz bucaksız enginliğin gerçeklik- dışı haliyle karşıtlık oluşturan mutlak bir gerçek de açığa çıkarılır. Kutsalın tezahürü Dünyayı ontolojik açıdan kurar. Hiçbir nirengi noktası saptamanın mümkün olmadığı, hiçbir yönün belirlenemediği türdeş ve sonsuz enginlikte hiyerofani mutlak bir "sabit nokta"yı, bir "Merkez"i açığa çıkarır. (Eliade 2017a: 22)}

Meyrink'in eserinde var olduğunu düşündüğümüz hiyerofaninin kendini hangi şekilde ortaya çıkardığını tespit etmek ve Radspieller'in inancıyla ilgili tecrübe ettiklerinin hayatında nasıl bir mekânsal değişim yarattığını ortaya koymak çalışmanın amacını oluşturur. Çalışmanın birinci bölümünde hiyerofani kavramı ile birlikte Eliade'nin Kutsal ve Kutsal-Dışı ${ }^{1}$ çalışmasında temel alınan bilgiler açıklanmaya çalışılacaktır. Eliade tarafından, "varoluşsal durumun ontolojik olgunluğu" (Eliade 2015b: 126) olarak tanımlanan erginlenme kavramı ise ikinci bölüm için önemlidir. Çalışmanın ikinci bölümünde, erginlenmenin ne şekilde gerçekleştiği Eliade'nin farklı çalışmalarında verdiği bilgiler doğrultusunda Kardinal Napellus eseri üzerinde incelenmeye çalışılacaktır. Meyrink'in eseri içeriği itibariyle dinsel öğeleri konu edinir. $\mathrm{Bu}$ durum eseri, Mircea Eliade'nin çalışmaları bağlamında incelenebilir kılmaktadır. Ağırlıklı olarak Eliade'nin eserlerinin, çalışmanın kuramsal temelini oluşturduğu yöntemle Meyrink'in öyküsü analiz edilecektir.

\footnotetext{
1 Profan olarak da adlandırılan ve kutsalın karşıtı olarak kullanılan kutsal-dışı kavramı, Duden Fremdwörterbuch sözlügünde: "vor dem heiligen Bezirk liegend, ungeheiligt; gewöhnlich, weltlich, unkirchlich; ungeweiht, unheilig; Ggs. sakral. alltäglich” olarak tanımlanır (Wermke 2001: 808).
} 


\section{Mircea Eliade: Kutsal ve Kutsal-Dışı}

Kutsal olanın kendini bir nesnede varlığını hissettirmesi ve bunu bu dünyadaki insanlar için görünür kılması yani kutsalın tezahürü Mircea Eliade tarafindan Hiyerofani olarak tanımlanır (Eliade 2017a: 15). Bütün dinlerde hiyerofani örnekleriyle karşılaşılabileceğini ifade eden Eliade, bu kavramı: “' [...] Bambaşka türde’ bir şeyin, bizim dünyamıza ait olmayan bir gerçekliğin bizim 'doğal', 'kutsal-dışı' dünyamızın bir parçası olan nesnelerde tezahürü” (Eliade 2017a: 15) olarak açıklar. Örneğin, özellikle daha eski inançlarda bir ağaca tapınılmasının altında yatan neden artık ona tapanlar için onun bir ağaç olmaktan ziyade kutsalı ihtiva eden ve bunu gösteren bir nesneye dönüşmesi ile ilgilidir (Eliade 2017a: 15). Eliade daha ayrıntılı olarak bu konuda şunları söyler:

Bir taşın kutsallığını görenler için ise, onun doğrudan gerçekliği doğaüstü bir gerçekliğe dönüşür. Başka bir ifadeyle, dinsel bir deneyim yaşayanlar açısından tüm Doğa kozmik bir kutsallık olarak belirmeye müsaittir. Kozmos bütünüyle bir hiyerofani olabilir. (Eliade 2017a: 16)

Eliade'nin hiyerofani kavramı dışında ele aldığı önemli bir konu da dinsel insanın, (Eliade 2017a: 16) kutsal olana yakın olma arzusudur. Ona göre, dinsel insan, "kutsal bir evren" içinde kalmaya çalışır (Eliade 2017a: 16). Eliade, "kutsal/kutsal-dış1 karşıtlığı" (Eliade 2017a: 16) çalışmasının bir çok yerinde dile getirir. Bu noktada dinsel insan için kutsal mekânın nasıl bir öneme sahip olduğu konusu önemlidir. Eliade, dinsel insan için bölünmelere ve kopmalara sahip olan bir mekânın türdeş olmadığını belirtir ve şunları ifade eder:

Dinsel insan açısından uzam türdeş değildir; kopuşmalar, kırılmalar içerir: Uzamın bazı bölümleri nitelik olarak ötekilerden farklıdır. "Tanrı [Musa'ya], 'Fazla yaklaşma' dedi, 'Çarıklarını çıkar. Çünkü bastı̆̆ın yer kutsal topraktır’” (Mısır'dan Çıkış III:5). Demek ki kutsal, dolayısıyla "kuvvetli", anlamlı uzam ve bir de kutsanmamış, dolayısıyla belli bir yapısı ve istikrarı bulunmayan, kısacası şekilsiz uzamlar vardır. Bunun da ötesinde: Dinsel insan açısından, bu uzamsal türdeşlik yokluğu tek hakiki uzam olan, hakikaten var olan kutsal uzam ile tüm geri kalan, onu çevreleyen şekilsiz uzam arasındaki karşıtlık deneyimi olarak yansır. (Eliade 2017a: 21)

Eliade'nin verdiği bu bilgiler doğrultusunda bir sonraki bölümde Kardinal Napellus eserinde en azından hayatının belli bir döneminde dinsel insan olarak tanımlanabilecek Radspieller adlı ana figürün yaşamının, dinsel insan olmaktan, dinsel olmayan ya da kutsal olmayan (profan) bir insanın yaşamına dönüşmesinde etkili olan hiyerofani ve bu hiyerofaninin etkili olduğu erginlenme ele alınacaktır. Erginlenme konusu çalışmanın akışı gereği eserin analiz edildiği diğer bölüm içinde açıklanmaya çalışılmıştır. Bu noktada Radspieller'in kutsalın tezahür etmediği bir yerde kendine yeni bir dünya kurma çabası mekânsal açıdan da değerlendirilmeye çalışılacaktır. 


\title{
2. Kardinal Napellus Adlı Eserde Hiyerofani Olarak Mavi Kurtboğan Bitkisi Ve Onun Erginleyici Rolü
}

Gustav Meyrink'in bu öyküsünde eskiden bir keşiş olan yaşlı Hieronymus Radspieller'in hem keşiş olduğu dönemde hem de keşiş olmayı bırakıp öykünün de anlatıldığı mekân olan medeniyetten uzak bir yerde yaşadığı tuhaf olaylar anlatılır. Radspieller'in kiraladığı köşkte geçici olarak bulunan, öykünün diğer figürleri de ana figürün başına gelen olaya şahitlik ederler. Kötü bir halde olan köşkün bir katını kiralayan Radspieller, orayı antika eşyalarla doldurmuştur. Köşk, dış dünyadan, medeniyetten uzak, izole bir yerde bulunmaktadır:

\begin{abstract}
Çürümüş, karmakarışık saçaklı porsukağaçlarının rüzgarın şiddetinden arada bir korkuyla inlemeleri ya da koyu yeşil gölün, sürüklenen beyaz bulutları gökyüzüne dik dik bakan bir göz gibi yansıtması dışında, hayat tarafından terk edilmişe benzeyen, asla bir kuşun ötmediği 1ssız bölgeden geçip de bu kattaki odalara adım atmak keskin, fantastik bir tezatt1. (Meyrink 2016: 30)
\end{abstract}

Köşkün bulunduğu yer ile Radspieller'in oturduğu katın sahip olduğu bu özel zitlık okuyucuya öykünün başında fantastik bir olayın yaşanacağına dair bir ön bilgi verir.

Öykünün devamında Radspieller'in neden bu yerde bulunduğu açıklık kazanır. Onun tüm gününü sandalda geçirdiği ve "[...] incecik ipek iplerin ucundaki parlak metal bir yumurtayı-gölün derinliğini ölçmeye yarayan bir iskandil-durgun suya daldır[dığı]" okunur (Meyrink 2016: 30).

Başlangıçta köşkte bulunan diğer figürler, Radspieller'in bir coğrafya kurumunda çalıştıklarını düşünürler, ancak daha sonra Mr. Finch, Radspieller'in gençliğinde keşiş olduğu dönemde her gece kendini kanlar içinde kalıncaya kadar kamçıladığını yaşlı bir ulak kadından öğrendiğini söyler. Öykünün bu noktasında eserde yer alan diğer iki figürün adını öğreniriz: Giovanni Braccesco ve botanikçi olan Eshcuid. Bunların dışında öyküyü anlatan anlatıcının ismi konusunda eserde herhangi bir bilgi verilmez. Botanikçi olan Eshcuid elinde bir bitki ile gelir. Radspieller' in hayatı ve onun yaşadıkları için bir kilit noktası görevi gören ve dolayısıyla eserin merkezini teşkil eden bu çiçek şöyle tasvir edilir:

Çelik mavisi parlayan çiçekleri ${ }^{2}$ olan, insan boyunda bir bitki tutuyordu elinde. Bizi başıyla selamladıktan sonra, "Bu türün şimdiye kadar bulunmuş en büyük örneği; zehirli ‘mavi kurtboğan'ın bu irtifada yetiştiğini hiç sanmazdım.” (Meyrink 2016: 31)

Radspieller, gölden döndükten sonra balıkçılıkla uğraştıkları anlaşılan figürlerden Braccesco balık avlamak ile ilgili farklı teknikler hakkında konuşmaya başlar. O, anlatırken Radspieller birden konuşmaya başlar ve uzun süredir suyun altında oluşan girdaplar yüzünden bir türlü iskandilinin gölün dibine ulaşamadığını ancak o gün "[d]ünyanın, insan elinden çıkma bir aletin ulaştığı en derin noktası[na]" (Meyrink 2016: 33) iskandilinin ulaştı̆̆ını ifade eder. Radspieller'in bu cümleleri anlatıcı üzerinde farklı bir etki yaratır:

\footnotetext{
${ }^{2}$ Öyküde bir leitmotif olarak önemli bir role sahip mavi kurtboğan bitkisi (Aconitum Napellus) ve onun bu alıntıdaki tasvirinde yansıtılan çiçekleri, Romantik dönemde karşımıza çıkan ve özlemi [alm. Sehnsucht] hatırlatan mavi çiçek [alm. Blaue Blume] motifini akla getirir (krş. Grabert 1983: 162).
} 
Bakışlarımı Radspieller'in yüzünden ayıramıyordum; bir anda nasıl da hayaletimsi, gerçekdışı bir havaya bürünmüştü! Gözlerimi bir an kapadığımda, yüzünün mavi alevler arasında parladığını gördüm; dilimin ucuna gelen "Ölümün Aziz Elmo Ateşi" kelimelerini haykırmamak için dudaklarımı sımsıkı kenetledim. (Meyrink 2016: 33-34)

Anlatıcı tarafından Radspieller ilgili yapılan bu tasvirler öykü anlatımındaki fantastik unsurları daha yoğun bir şekilde ortaya çıkarır. Bu noktadan sonra Radspieller'in yaşadıklarını kendi ağzından anlatmaya başlaması ile en başından itibaren okuyucuya örtük bir şekilde hissettirilen fantastik ${ }^{3}$ izler daha açık bir şekilde öyküde görünür hale gelir. Anlatılanlardan Radspieller'in gençliğinde keşiş olmasına rağmen hayatının sonraki döneminde gençliğinde inandığ kutsal şeylerden vazgeçen biri olduğu anlaşılır. Dünyanın en derin noktasının keşfedilmesinin bilimsel öneminden ziyade kendi için farklı bir anlamı olduğunu ifade eder ve yaşadıklarını anlatmaya başlar Radspieller. Aslında hiçbir zaman tam olarak bir din adamı olmadığını ama içindeki bir şeylerin onu bir şekilde dünyevi şeylerden uzaklaştırdığını anlatır.
Hayatım manevi susuzluğun bitmek bilmeyen işkencesine dönüştü yavaş yavaş. Artık ne uyuyabiliyor ne de düşünebiliyordum; dudaklarım gece gündüz hiç durmadan seğiriyor, kıpırdıyor ve bitkinlikten bilincimi yitirene kadar mekanik bir biçimde, 'Kötülükten kurtar bizi!' diye dua ediyordum.
Yurdumun vadilerinde, 'Mavi Biraderler' denen ve sonlarının yaklaştığını hisseden üyelerinin kendilerini toprağa diri diri gömdürdüğü bir tarikat vardır. Manastırları bugün halen ayakta, giriş kapısının üstünde taştan bir arma asılı: Beş mavi taçyaprağından en üstteki keşiş kukuletasına benzeyen zehirli bir bitki: Aconitum napellus, 'mavi kurtboğan'. (Meyrink 2016: 37-38)

Radspieller'in keşiş olarak yaşadığı manastır, kutsal ya da dinsel bir mekân olması açısında bir heterotopya olarak tanımlanabilir. Michel Foucault, heterotopyalar ile ilgili belirlediği ilkelerden birini şöyle açıklar:

\begin{abstract}
Heterotopyalar her zaman bir açılma ve kapanma sistemi gerektirirler; bu, heterotopyaları hem tecrit eder hem de nüfuz edilebilir k1lar. Genel olarak, heterotopik bir mevkiye bir değirmene girilir gibi girilmez. Ya orada zorla kalınır; kışlanın, hapishanenin durumu budur ya da kurallara ve arınmalara boyun eğmek gerekir. Oraya ancak belli bir izinle ve belirli davranışları yerine getirdikten sonra girilebilir. (Foucault 2014: 300)
\end{abstract}

Manastırda kalması ve oradaki üyeliğini devam ettirebilmesi için yerine getirmesi gereken ritüel, yani mavi kurtboğan bitkisini kanı ile sulaması, Foucault'nun heterotopyalar için belirttiği ilke doğrultusunda düşünüldüğünde manastırı bir heterotopya olarak tanımlanabilir kılar.

Çok genç yaşta girdiği bu tarikattan bir ihtiyar olarak ayrılan Radspieller, manastırın bahçesinde yetiştirilen bu bitkiyi keşişlerin kırbaçladıkları kendi bedenlerinden akan kan ile suladıklarını anlatır. Geleneğe göre her keşişin kendine ait

\footnotetext{
3 Tzvetan Todorov, fantastik türe dair, "saf tekinsiz, tekinsiz fantastik, olağanüstü fantastik ve saf olağanüstü” olmak üzere dört farklı alt sınıflama yapar (Todorov 2012: 50). Yapılan bu çalışmanın kapsamı nedeniyle, Meyrink'in öyküleri üzerine yapılacak başka bir çalışmada bu sınıflandırma üzerinde daha ayrıntılı bir şekilde durulması gerektiği düşünülmektedir.
} 
çiçeğe vaftiz töreninde gelenek olduğu üzere bir Hristiyan ismi vermesi gerekir. Radspieller'in kendi çiçeğine verdiği isim ise Hieronymus'dur.

$\mathrm{Bu}$ noktada Eliade'nin vaftiz töreni ve erginlenme konusunda söyledikleri, eserin analizi için önemli bir temel oluşturur. Eliade, "Doğuş ve Yeniden Doğuş" (2015a) çalışmasında erginleme ritüellerinin farklı kültürlerde ve onların inançlarında farklı şekillerde gerçekleştiğini ifade eder. Erginlenme kavramını ise genel olarak şöyle tanımlar:

Erginleme (initiation) terimi, en genel anlamda, maksadı erginlenecek olan şahsın sosyal ve dini statüsünde kesin bir değişim meydana getirecek olan ritüeller ve öğretiler bütününe işaret eder. Felsefi terimlerle ifade edilecek olursa erginleme, varoluşsal durumda temel bir değişime denk düşer; aday, sınavından, erginleme ritüelinden önce sahip olduğundan tamamen farklı bir beden olarak ortaya çıkar ve bir başkası haline gelir. (Eliade 2015a: 12)

Eliade tarafından, "Erginleyici ölüm, [..] daha yüksek bir varlık biçimine doğum” olarak tanımlanır. (Eliade 2015a: 18). Birçok dinde ve inançta olduğu gibi çekilen çilelerden sonra erginlenme gerçekleşir (krş. Eliade 2015a: 248). Eliade, Hristiyanlık dininde de en önemli erginlenme ritüllerinden birinin vaftiz olduğunu söyler: "Hristiyanlıkta, bir erginlenmeye karşılık gelen şeylerin ilki, Hristiyan vaftizidir" (Eliade 2015a: 228).Vaftizin buradaki önemi, kişinin dini topluluğa kabulü olarak tanımlanır (Eliade 2015a: 228).

Vaftiz, yeniden doğumu simgeleyen bir erginlenme ritüelidir (krş. Eliade 2015a: 228). Eliade'nin, vaftiz ile ilgili önemli bir tespiti de Rahner'in çalışmasına atıfta bulunarak vaftiz kurnası ile ilgili verdiği bilgilerdir:

Vaftiz kurnası, hem mezarla hem de rahimle karşılaştırılır; vaftiz, din eğitimi gören kimsenin (catechumen) kendi dünyevi hayatını gömdüğü mezar ve kendisiyle ebedi hayata doğduğu rahimdir. (Eliade 2015a: 234)

Eliade'nin erginlenme ve vaftiz hakkında verdiği bu bilgiler doğrultusunda yapılan bu çalışmada incelenen Meyrink'in Kardinal Napellus adlı eserinde de erginlenme olarak tanımladığımız-ki eserde de bunun bir çeşit vaftiz olarak kabul edildiği söylenir-ritüel, Radspieller'in bağlı bulunduğu topluluk üyelerinin kendi kanı ile mavi kurtboğan bitkisini sulamalarıdır. Burada bu bitkinin, Kardinal Napellus'un kutsal tezahürü olması ve keşişlerin erginlenmeleri açısından önemli bir rol oynadığı görülmektedir.

Eserde kan ile beslenen bitki, kişinin yeniden doğuşunun ve erginlenmenin anahtarıdır. Burada bitkinin bulunduğu toprağın bir vaftiz kurnasının sahip olduğu mezar ve rahmin sembolik anlamı ile benzerlik gösterdiği ifade edilebilir. Normal olarak bir vaftiz töreninde kullanılan su yerine eserde Radspieller'in bağlı bulunduğu topluluğun daha katı inançları ile bağlantılı olarak bu erginlenme, kan ile gerçekleştirilir. Suyun, arındıran ve yaşamı besleyen işlevi (krş. Eliade 2017b: 171) eserde kan ile yer değiştirmiştir.

Radspieller, yıllarca çiçeğini sulamasına rağmen, beklediği mucizenin bir türlü gerçekleşmediğini ve buna karş1lık kendini tükettiğini anlatır. Gerçekleştirilen bu törenin amacı ise, "insanın ruhunu büyüyle cennet bahçesine dikmesi ve arzularının 
kanıyla gübrelemesi[...]" olarak açıklanır (Meyrink 2016: 38). Eserde bu çiçeğin ortaya çıkışı ile ilgili efsane şöyle anlatılır:

\begin{abstract}
Söylenceye göre, dünyadan el etek çekmiş bu tarikatın kurucusu efsanevi Kardinal Napellus'un mezarından bir dolunay gecesinde adam boyunda bir 'mavi kurtboğan' fışkırmış - her tarafı çiçekle kaplıymış - ve mezar açıldığında, içindeki cesedin ortadan kaybolduğu görülmüş. Azizin bitkiye dönüştüğü ve bütün kurtboğanların dünyada ilk o zaman yetişmiş bu bitkiden geldiği söylenir. (Meyrink 2016: 38)
\end{abstract}

Burada, kardinal gibi kutsal bir şahsiyetin bedeninin ortadan yok olması ve bir bitki olarak kendini göstermesi, bir hiyerofani yani kutsalın tezahürü olarak yorumlanabilir.

Eserin devamında keşişlerin bu çiçeğin zehirli tohumlarını mucizevi güçlere sahip olabilmek için yedikleri anlatılır. Ancak Radspieller, mantıklı bir şekilde bu çiçeğin zehriyle kanına ne olacağını sorar.

İşte o zaman etrafımdaki her şey canlandı, yoldaki taşlar bile bana binlerce ağızdan haykırdı: Her ilkbaharda kanın tekrar tekrar akıtılacak ki, senin adını taşıyan yeni bir zehir bitkisi daha fışkırsın. (Meyrink 2016: 39)

$\mathrm{Bu}$ durumun içinde yarattığı nefretle Radspieller, bahçede kendi adını taşıyan bitkiyi ayaklarıyla ezerek yok eder. Bunu yaptığı günün gecesinde Kardinal Napellus'un elinde zehirli mavi çiçeği tuttuğu ve Kardinalin yüzünün kendi yüzüne benzediği bir rüya görür. "Kardinal Napellus elinde - parmaklarının duruşu, yanan bir mum taşıyan bir insanınki gibiydi - beş taçyapraklı mavi çiçeği tutuyordu", diye anlatır Radspieller (Meyrink 2016: 40). Bu rüyadan sonra manastırın yemekhanesinde kardinalin emanetlerinin tutulduğu sandığı parçalar ve içinden azize ait bir yerküreyi yanına alarak manastırdan kaçar. Bu kaçışından sonra sürekli olarak tuhaf bir şekilde eski hayatının parçaları ile karşılaşır. Örneğin bir satıcının eşyaları arasında tesadüfen üzerinde bir zamanlar ait olduğu topluluğun armasını taşıyan bir yüzük bulur, ya da azize ait bir kutsal emanet olan yerküre, - ki onu da manastırdan kaçarken yanında götürmüş ve satıp parasını bir hayat kadınına vererek azizi aşağılamayı düşünmüştü -, bir arkadaşı tarafından ona hediye olarak tekrar gönderilir. Bu olaylardan sonra her şeyden uzak olmak amacıyla şu anda yaşadığı yere yerleşir. Radspieller, o bölgeyi tercih etme sebebini " [...], buralara, karlı dağlar diyarının berrak, hafif havasına inancın ve umudun zehri nüfuz edemez, mavi kurtboğan bu yüksekliklerde yetişemez" diyerek açıklar (Meyrink 2016: 41). Böylelikle Radspieller, gençliğinde dinsel bir hayatı varken yaşadıkları yüzünden bu hayattan vazgeçer ve kendini tamamen her türlü dinsellikten ve mucizeden uzak bir yaşam sürmeye adar. ${ }^{4}$ Bunun için de özellikle önceki hayatının simgesi olan mavi kurtboğanın asla yetişemeyeceği bir yeri tercih eder. Eliade'nin bakış açısı ile ele alırsak, Radspieller, dinsel bir insan olarak kutsal olana yakın yaşarken sonrasında kendini tamamen kutsal olan mekândan ve kutsallıktan uzaklaştırır. Bu durum, onun ifade ettiği "' [a]rtık iyileştim; melekler aleminin tüm mucizeleri kucağıma düşse bile, onları değersiz ıvır zıvır gibi fırlatıp atardım. Varsın mavi kurtboğan,

\footnotetext{
${ }^{4}$ Radspieller'in hayatının keşişlikten sonraki dönemini geçirmek istediği ve mavi kurtboğan bitkisinin yetişmeyeceğine inandığ bu yer 1ssız, izole ve dış dünyaya daha kapalı konumu ile bir heterotopya olarak tanımlanabilir.
} 
kalbinden hastaların, vadilerdeki dermansızların zehirli ilacı olmaya devam etsin[...]"' cümlelerinde daha açık bir şekilde görülmektedir (Meyrink 2016: 41). Radspieller, bütün bunlardan uzakta yaşamaktan oldukça memnun olduğunu belirtir. Göle iskandil atmasının sebebini ise şöyle açıklar:

Dünyanın kabuğunda, güneşin döllediği korkunç zehirler yetişse de, dünyanın içi, uçurum ve çukurları bunlardan azadedir ve derinlikler saftır. [...] Nereye bakarsanız bakın, dünya sadece dünya! (Meyrink 2016: 42)

Eserin son sayfalarında Radspieller, kendinden emin bir şekilde onu da etkilemesi gereken ama gerçekleşmediğine inandığ bir kehanetten bahseder:

Her kim mistik bitkiyi sonuna kadar kanıyla sularsa, bitki o kişiyi ebedi hayatın kapısına götürür; ama her kim bitkiyi söküp atarsa, o caniye ölüm olarak görünür ve caninin ruhu, yeniden bahar gelene kadar karanlıklarda dolanır durur! (Meyrink 2016: 43)

Radspieller, bu kehanetin de gerçekleşmemesini kendini haklı çıkaran bir kanıt olarak gösterir. Ancak botanikçinin pencerenin önüne koyduğu mavi kurtboğan çiçeğini gördüğünde her şey bir anda değişir. Tam o sırada, Eshcuid'in azizin yerküresini incelemek için eline aldığında bulundukları yerdeki gölün üzerine iğne batırması sonucu yerkürenin üzerindeki kabuk soyulur ve bir cam küre ortaya çıkar. Bu kürenin içinde tıpkı Radspieller'in rüyasında gördüğg̈ gibi “cübbesi ve şapkasıyla dimdik ayakta duran ve parmaklarının duruşu yanan bir mum taşıyan insanınkini andıran, elinde beş taç yaprakl1, çelik mavisi bir bitki tutan kardinal figürü” görülür (Meyrink 2016: 44). Radspieller bu figürü de gördüğünde adeta olduğu yerde donakalır. Anlatıcı, onun bu halini şöyle tasvir eder:

Henüz hayatta olduğu, sadece gözlerindeki parıltıdan belliydi; fakat biz, ruhunun çılgınlığın karanlığında ebediyen kaybolduğunu anlamıştık. (Meyrink 2016: 44)

Öykünün sonunda eserin diğer figürleri köşkten ayrılırlar ve yıllar sonra anlatıcı tekrar köşkün bulunduğu yerden geçerken, sadece bahçe duvarları kalan köşkün yıkıntıları arasında çok sayıda mavi kurtboğan bitkisi ile dolu olduğunu görür. Ve öykü bu şekilde sonlanır.

Eliade, "[...] dini tecrübe, dünyanın ikiliğini "kutsal" ve "kutsal olmayan" olarak varsaymaktadır" (Eliade 2015b: 146) der. Kutsal ve kutsal olmayan ya da kutsal dışı zıtlık, Meyrink'in Kardinal Napellus adlı eserinde Radspieller' in yaşam öyküsünde kendini gösterir. Gençlik döneminde kutsal ya da dinsel bir yaşam sürerken sonrasında kutsal olmayan, kutsal dışı bir yaşam sürdürmeyi tercih eden Radspieller, kutsal olandan kendini uzaklaştırır, ancak bu konuda başarısızlığa uğrar. Çünkü terk etmek istediği eski yaşamı sürekli olarak farklı tesadüflerle onun peşini bırakmaz.

\section{Sonuç}

Gustav Meyrink'in Kardinal Napellus adlı eserinde Radspieller'in kutsal olandan kaçma ve bundan uzak bir yaşam sürme çabasının başarısızlığa uğradığı görülür. Her ne kadar kutsal olandan kaçabildiğini sansa da yaşadığı tesadüf gibi görünen olaylar ile 
kurtulmak istediği şeyden asla kurtulamadığ 1 ve hatta en sonunda yaşanan durumla onun için de kehanetin bir şekilde gerçekleştiği görülür. Eliade'nin kutsalın tezahürü olarak ifade ettiği hiyerofani kavramı burada kendini mavi kurtboğan bitkisi olarak gösterir ve Radspieller ve onun gibi keşişlerin erginlenmesinde önemli bir etkiye sahip olduğu görülür. Azizin mezarından fişkıran bu bitkide, kutsal olan tezahür eder. Radspieller'in kutsalın kendine ulaşamayacağına inandığı bir yerde dahi kutsal, bu bitki ve azize ait olan kutsal nesneler ile karşısına çıkar ve onun peşini bırakmaz. Başka bir deyişle kutsalın tezahür etmediği bir yer arayışı onun için başarısızlıkla sonlanır ve kutsallığın dokunmadığına inandığı bir yerde bile, kutsal olan ile yüzleşmek zorunda kalır.

Radspieller'in önceki dinsel hayatının tersine kutsallıktan uzak bir dünya kurmaya çalıştığı görülür. Dinsel insanın kendi evrenini kurmaya çalışırken temel aldığı kutsal olana yakın olma isteğinin (krş. Eliade 2017a: 22) karşıtı olarak Radspieller, kutsal dişı olan bir evreni yani mavi kurtboğan bitkisinin yetişmediği bir yerde kutsallıktan uzaklaşmaya ve kendisi için kutsal dışı (profan) bir evren kurmaya çalışmış, ancak bu çabası sonuçsuz kalmıştır.

\section{Kaynakça}

Birincil Kaynaklar:

Meyrink, Gustav (2016): Kardinal Napellus, (Çev. Z. A. Y1lmazer), İstanbul: Kırmızı Kedi Yayınevi.

\section{Íkincil Kaynaklar:}

Bark, Joachim vd. (Ed.). (1997): Geschichte der deutschen Literatur, Vom Naturalismus zum Expressionismus, Literatur des Kaiserreichs. Heilbronn: Ernst Klett Schulbuchverlag.

Eliade, Mircea. (2015a): Doğuş ve Yeniden Doğuş, İnsan Kültürlerinde Erginlenmenin Dini Anlamlarl, (Çev. F. Aydın), İstanbul: Kabalcı Yayıncılık.

Eliade, Mircea. (2015b): Dinin Anlamı ve Sosyal Fonksiyonu, (Çev. M. Aydın), İstanbul: Kabalcı Yayıncilik.

Eliade, Mircea. (2017a): Kutsal ve Kutsal-Dışı, Dinin Doğası, (Çev. A. Berktay), İstanbul: Alfa Yayınları.

Eliade, Mircea. (2017b): İmgeler ve Simgeler, (Çev. M. A. Kılıçbay), Ankara: Doğu Batı Yayınları.

Eliade, Mircea. (2017c): Mitler, Rüyalar ve Gizemler, (Çev. C. Soydemir), Ankara: Doğu Batı Yayınları.

Foucault, Michel. (2014): Özne ve İktidar, Seçme Yazılar 2. (Çev. I. Ergüden, O. Akınhay). İstanbul: Ayrıntı Yayınları.

Grabert, Willy, vd. (Ed.) (1983): Geschichte der deutschen Literatur. München: Bayerisher SchulbuchVerlag.

Lutz, Bernd. (Ed.) (1986): Metzler Autoren Lexikon, Deutschsprachige Dichter und Schriftsteller vom Mittelalter bis zur Gegenwart, Stuttgart: J.B. Metzlersche Verlagsbuchhandlung.

Martini, Fritz (1991): Deutsche Literaturgeschichte, Von den Anfängen bis zur Gegenwart. 19. Bask1. Stuttgart: Alfred Kröner Verlag. 
Todorov, Tzvetan. (2012): Fantastik, Edebi Türe Yapısal Bir Yaklaşım, (Çev. N. Öztokat), İstanbul: Metis Yayınları.

Wermke, Matthias, vd. (Ed.) (2001): Duden, Fremdwörterbuch, Band 5, 7., neu bearb. und erweiterte Aufl. Mannheim: Dudenverlag. 